\title{
Improvement of the Relation between Existing Techniques of Product and Food Protection and Drugs Safety Management
}

\author{
Ivan Spirydonau \\ Department of Business, Government and Philosophy, School of Economics via Columbia, Tor Vergata University of Rome, Rome, Italy \\ Email: ispirydonau@gmail.com
}

How to cite this paper: Spirydonau, I. (2016) Improvement of the Relation between Existing Techniques of Product and Food Protection and Drugs Safety Management. Open Journal of Social Sciences, 4, 43-52. http://dx.doi.org/10.4236/jss.2016.411003

Received: September 8, 2016 Accepted: November 22, 2016 Published: November 29, 2016

\begin{abstract}
The goal of this paper is to assess the existing methods of food and drugs safety management from the standpoint of product packaging and labeling. Several methods of safety management have been introduced in order to protect both supply chains and consumers from fake commodities, yet their effectiveness is a relevant question since counterfeiters keep up with the development and implementation of advanced protective means. Since verifying drugs' authenticity is a crucial issue nowadays and fake commodities represent significant economic and societal challenges, a new set of counter-measures must be put in place to address the advancing growth of the counterfeit threat. A conceptual model will be used to assess the existing problems of food and drug safety, and practical implications will be derived out of the real life situations that occurred with pharmaceutical manufactures. Analysis of the existing ways of how essential commodities are protected and propositions on how these ways could be upgraded will improve the understanding of food and drugs safety management. The improved system of food and drug safety management implies a set of actions that have to be undertaken in order to form a solid, unified system and thus provide complete assurances of a product's safety. Not only does the security of supply chains and product traceability systems need improvement, but also existing public policies regarding compulsory food and pharmaceutical certifications need to be reviewed.
\end{abstract}

\section{Keywords}

Safety Management, Product Authenticity, Counterfeit, Supply Chain Security

\section{Introduction}

Production outsourcing hurdled the logistics to the extent when control over safety and 
authenticity of merchandise has been dramatically reduced. These conditions allowed counterfeit manufacturers and unauthorized retailers to establish their own production and distribution networks or infiltrate already existing supply chains and derive huge amounts of profits by trading low quality substandard commodities. One of the most targeted category of products is pharmaceuticals and hygiene products. This study will outline major problems that are caused by fake pharmaceutical trade and identify the most viable prevention mechanisms that could be deployed in order to reduce the global retail of potentially dangerous unlicensed medicine. The methodology for this study is primarily represented with a qualitative analysis: review of the literature; observation of the main tendencies, policies, and industry trends as well as analyses of specific cases related to drug forgery. Comparative analysis of the literature on counterfeit prevention methods and data from the real life examples will provide a solid background for the identification of the actual problems companies and governments are faced with. The research will not simply analyze holistic characteristics of the illegal trade of spurious drugs and counterfeit medical substances, but will also make an attempt to deliver appropriate solutions to confront the existing problems both effectively and efficiently.

\section{Purpose of the Study}

Due to the high level of accessibility and high development of printing technologies, counterfeiters are quite capable of producing products and product packages that look exactly the same but could be lethal for the consumer. However, besides negative consequences that fake drugs have on consumers, government and entrepreneurs are also loosing profits in terms of taxes or brand value. Import and sales taxes are avoided due to the illegal nature of transportation which leads to reductions in the tax base, and thus negatively affects public wealth. As far as the private entities are concerned, retail of counterfeits under well-recognized trademarks can affect the public image and brand appreciation of a company and decrease customers' loyalty, since it might be perceived as if the firm is not able to provide necessary security for its product and prevent illegal production of its branded goods. All of these problems cannot be neglected and counterfeit of medications cannot be observed as a victimless crime. Furthermore, there are registered deaths caused by fake drugs in Africa and other health problems caused by substandard quality medications [1]. This shows that there is a clear need to go beyond generally accepted public policies on counterfeit trade prevention and pay more attention to combining already existing technologies and supporting their implementation with the state-level regulations or corporate policies.

The most innovative aspect of the research is that it offers a set of already existing techniques and does not imply the compulsory usage of any of these techniques. Rather, it provides a set of concepts on how the combination of advanced technologies could be used to ensure products' legitimacy and originality.

\section{Defining Fake Drugs}

Despite the fact that every country uses its own definition to refer to counterfeit and 
substandard quality medicine, the principle is the same-fake pharmaceuticals may contain wrong ingredients, may lack active ingredients or insufficient amount of active additives, and are usually labeled as original products. One of the most referred to definitions is provided by World Health Organization (WHO) and describes counterfeit pharmaceuticals as the ones to be "deliberately and fraudulently mislabeled with respect to identity and/or source" [2]. Fake drugs are usually contained in packages resembling original ones and have the same exact style and design, making it extremely hard for both consumers and authorities to verify authenticity. According to the report comprised by United Nations Interregional Crime and Justice Research Institute, it has been estimated that "the global counterfeiting of pharmaceuticals rose by $40 \%$, with the corresponding economic losses amounting to more than $€ 2$ billion, between 2004 and 2005 alone" [3]. Many other sources highlight the vast magnitude of the phenomenon pointing out major problems and tendencies. Experts define two major categories of counterfeit drugs based on the presence of active ingredients. The first group is pharmaceuticals that have active additives but still lack the necessary effect on a patient due to low quality of other active ingredients that would activate the medication in the body. The other group refers to the ones that do not have the active formula and thus are completely inactive and have no effect on the patients. Fake drugs from both of these groups could have different, sometimes unpredictable, health effects, some of which may even be lethal.

\section{Major Problems}

Drug forgery is a phenomenon of large magnitude, since the costs of production are low and there is no need to incur additional marketing costs in order to sell merchandise. Usually, low quality cheap substitutes are used for the production of fake drugs, and the manufacturing process does not require highly developed infrastructure and facilities. Since counterfeiters do not bear the responsibility for their commodities, and in case of detention all the blame usually goes to the official brand owner, the quality of final products, as well as labor conditions and production quality do not play a key role during assembly procedures.

\subsection{Transportation and Distribution}

Transportation and dissemination of fake pharmaceuticals could occur by the means of well-established distribution channels. According to Europol, brokers are the major players in diverting merchandise and infiltrating supply chains with an aim to sell fake medicine in the countries where prices for the products are higher. Factors such as excess of supply in one country and high demand in another may cause brokers to relabel medical products and transport them to the country where there is a higher price or a higher demand from the place where there is an excess of supply, thus earning significant yields and violating transportation and distribution policies. Several cases that occurred in the European Union reveal how fake commodities were transported, but these were detained consignments and there is no data on the actual size of fake phar- 
maceutical traffic due to the inability to control the flows of merchandise as well as channels of distribution [4]. Infiltration of the supply chains by counterfeit commodities usually occurs in developing countries, where there are no strictly outlined regulations regarding penalties and exact definitions of fake pharmaceuticals trade. However, not only developing countries experience high presence of illegal actors, since advanced economies are also becoming victims, due to policies such as free transportation of goods or free trade agreements that simplify transportation procedures.

According to the study performed by Interpol, legal supply chains are not the only methods of fake medication distribution, since criminal groups employ informal network structures [5]. Such networks are primarily operated by thousands of affiliate web resources which creates numerous challenges to trace the principal network website and reveal the main supplier. Affiliate websites are commission based operated and could be easily replaced in case of detention. Addressing internet trade of fake drugs poses serious challenges, since it requires cooperation of domestic and international law enforcement agencies [6]. However, online affiliates and retailers are not the only ones who manufacture illicit pharmaceuticals or substandard quality medications. A large share of counterfeit products are purchased from the producers and then sold via internet [7] and delivered to final consumers through postal services or delivery agents. The country of provenance is usually India or China, but due to the relabeling procedures and indicated locations of retailers/postal senders, final consumers are getting deceived and believe that drugs were manufactured in countries with high quality standards, such as Belgium or Canada. Free Trade Economic zones represent another threat, since these places tend to be hubs used for relabeling and repackaging. One of the most vivid examples has been revealed in two European Union Member States where online retailers had a very sophisticated and well-structured system of affiliates keeping track of all commodities in the database and having an elaborate global structure. The representatives of this network were located in several countries and the business structure resembled legally operated organization [8].

\subsection{Places}

The main locations where fake drugs have a high presence are India, Malaysia and China. Approximately thirty percent of all fake pharmaceuticals that are sold worldwide are manufactured in China [9]. The Indian government claims that only 0.4 percent of legal drugs in India are counterfeit, but WHO states that the actual percentage is around 20 [10]. According to the report composed by Interpol, fake drugs are present in practically all regions of the world, just to different extents. The scale of activity related to fake pharmaceuticals in Latin America, for example, during the years of 2008-2012, has been estimated to be a third of the legal volume. Legal volume was estimated to be USD 100 million, while USD 30 million belonged to illegal operators. According to World Health Organization and its survey conducted in African countries around 30 percent of all antimalarial medicines failed quality testing [11]. Counterfeit industry is approximated to be worth around USD 300 million, according to the esti- 
mations [10]. The Eastern European region is primarily targeted by counterfeiters with very specific types of doping substances. These data have been confirmed by several official and unofficial resources. The market counterfeiters tend to target with fake doping additives are athletes and bodybuilders who are interested in increasing their sport results. Since some people prefer to pay less and ignore the quality of the products, a certain percentage of athletes were purchasing fake items through their coaches and sports' clubs owners [5]. Lifestyle drugs represent one of the most targeted category by counterfeiters in the states of European Union.

One of the most recent cases occurred in Russia, where the internet was used as a major selling technique for an internationally known drug called Mildronate that has been produced in Latvia. A great share of Mildronate has been sold through the internet and was found to be illegally manufactured, because the origin of the merchandise was impossible to trace and pills did not have the proper percentage of active ingredients, according to experts from Roszdravnadzor-Federal Service for Surveillance in Healthcare. People were procuring the medication without prescription via the internet with private athletic purposes, since this medication increases recovery and bodybuilders were interested in this specific type of medication. Also, Mildronate is a cardio-vascular drug that could be used to treat different diseases caused by oxygen deficiency, atherosclerosis, heart failures, and heart attacks, functional disorders of heart and vessels, etc. According to Roszdravnadzor, there were several cases of Mildronate forgery detected in Russia after patients were hospitalized with breathing problems [12]. According to the labels contained on the packages Mildornate was produced in Slovakia and has been sold over the internet. All of these cases provide vivid examples that each region on the planet is targeted with a specific type of product and that counterfeiters are quite aware of the demands and supplies trends. Counterfeit drugs could be found anywhere on the planet [13]which makes it a global phenomenon that requires immediate and coherent action.

\section{Damage from Fake Pharmaceuticals-Economic and Public Health Effects}

There are several effects that fake drugs cause both in terms of public health and economic sustainability. According to AIFA and forensic tests they have performed during seizure operations, fake pharmaceuticals pose serious threats to public health [8]. The economic effects of redirected and forged pharmaceuticals are represented with large amounts of lost revenues and unpaid taxes. According to Interpol, the annual turnover of trade of diverted medicine, substandard quality pharmaceutical retail, and parallel trade accounted for USD 75 billion. Furthermore, US authorities detained an online criminal network that managed to earn USD 55 million in a two-year period [14]. "According to the International Institute of Research against Counterfeit Medicines (IRACM), USD 1,000 invested will generate a return of USD 20,000 in the trafficking of heroin, or a return of USD 43,000 for counterfeit cigarettes. With the same investment in counterfeit pharmaceuticals, crime groups can expect a return of USD 500,000. Eu- 
ropol estimates the annual turnover from pharmaceutical crime to be USD 75 billion" [15].

Fake drug trade is mostly conducted by an organized crime group (OCG) and has a direct relation to other forms of crime, such as document forgery, fraud, tax evasion, money laundering, terrorism, extortion and coercion [16]. It is also directly related to corruption and conflict of interests. Since public authorities, border guard and customs officials might be involved in assisting OCG representatives to conduct their illicit activities, it might be hard for authorities to put up with fake drug trade and reveal identities of those involved in the trade or document preparation. There were cases in European countries when pharmacists or doctors purposefully diverted original drugs and knowingly procured and prescribed counterfeit pharmaceuticals pursuing personal interests and receiving high commissions from shadow economy representatives [5]. A systemized anti-corruption strategy should be developed by the authorities that would enlist anti-counterfeiting policies and penalties for those who trade or manufacture spurious items. In many states, there is a problem of enforcement of the legislations regarding fake items trade and violation of Intellectual Property Rights (IPR), counterfeiters benefit more and thus harm the economies.

\section{Methods of Prevention}

There should be a high degree of political will and strong policies regulating import, certification, retail, and prescription of pharmaceuticals to address auxiliary challenges that legal parties are faced with. In many countries there are no specific legislations addressing and penalizing fake medicine production and distribution [7]. Usually, these types of activities fall under the category of intellectual property rights violations or fraud [5]. Inadequate implementation of drug regulation and lack of necessary legislations as well as inappropriate training of regulatory authority personnel also gives more incentives for organized crime groups to target specific markets and operate illegally. Interpol has initiated operation Pangea in 2008, and since that time more than 46,337 illegally operated online pharmacy websites have been shut down. In 2015 during Operation Pangea VIII, around 20.7 million fake and illicit medicines were seized, worth USD 81 million [14]. In collaboration with other authorities and intentional organizations this operation was quite successful and implied that local authorities should pay more attention towards control of the internet and the import and retail of fake drugs in their local territories. According to Bronshtein, in order to decrease the amounts of unlicensed pharmaceutical manufacture in China, home authorities need to address corruption on a local level and put in practice longer prison terms and well as financial sanctions for the illegal production of drugs [9].

In order to reduce the quantity of domestically retailed counterfeit drugs, state authorities should have proper monitoring systems that would allow for detection of spurious or illegal pharmaceuticals locally, where law enforcement and the public health sector would work closely together. One of the first steps that should be undertaken in terms of reducing the presence of fake drugs in the market is a database of legally im- 
ported, produced and retailed pharmaceuticals. This database should have entries from all parties that are involved in product-related transactions with a purpose of eliminating ambiguity and preventing unauthorized supply chain access [17]. The database should become a reference for all intermediaries within the supply chain and should provide product information for consumers and state officials upon request. The key point of this database-based system should be the complete cooperation between suppliers, distributors, retailers and consumers. The more information about each of these parties stored in the database, the less the risk of fake medicine entering the market [18]. The database could either be operated by the state authorities or organizations that unite pharmaceutical producers such as pharma trade associations.

Innovative features that could be placed on pharmaceutical packages represent a viable instrument in confronting the global issue of fake drugs trade. According to a study conducted by Lybecker, educating consumers and allowing them to ensure products authenticity would reduce the prevalence of fake pharmaceuticals on the markets [19]. For example, usage of polyester-based tamper evident seals on product packages, combined with the usage of covert images available only through special validators and securing blister foils with holographic hot stamping foil would increase package security and create complications during forgery and repackaging processes. The advantages of security printing are evident, since these means of protection, when combined together, would deprive counterfeiters of an incentive to incur additional costs in research and development activities to figure out the exact ways of how packages are protected with an aim to replicate the technology and forge product packages. Furthermore, tamper evident seal are well recognized by consumers and provide assurance that the product has not been accessed prior to the purchase.

However, security printing is not the only method that could be used to secure pharmaceuticals from forgery. With the development of a unified database, there is a chance to create an electronic pedigree for every single unit of merchandise and thus provide complete assurance about the product's authenticity. The track and trace technique of product authentication could be implemented to allow consumers, retailers, state officials, and other parties to receive information about the product and learn its lifecycle by the means of digital devices. Tracking techniques create obstacles for counterfeit traders since it makes it harder to infiltrate legal supply chains [20]. One of the most popular technologies that is used nowadays to secure products is RFID and Auto-ID based on RFID. Even though it is quite widespread, it has several disadvantages, mainly the cost. Auto-ID however, represents a viable approach towards securing pharmaceuticals as it allows instantaneous product authentication at any location [21]. Auto-ID systems also require a unified database and individual IDs for every single unit of merchandise, which increases package security and prevents counterfeiters from entering legitimate supply chains.

The alternative to RFID is Mass Encryption Technology, which gives every product a digital ID that is generated by the encryption engine. The encrypted code could be placed on the product package in the form of a well-recognized barcode, QR-code, 2-D 
data matrix barcode or any other readable code. Providing every single unit of merchandise with an encrypted digital code could increase package safety, due to the inability of counterfeiters to make entries to the database with encrypted codes. This technology empowers manufacturers to keep track of their commodities, enhances logistics, and allows them to manage supply chains and control shipments. According to Lybecker, counterfeiters have less incentive to strive to occupy a greater share of the market, when the risk of detention grows proportionally with the amounts of fake merchandise on the market. In her research, Lybecker also declares that implementation of technologically advanced methods of package protection would likely reduce the share of fake medicine and give more advantages to legal producers to fight counterfeiting crime [19].

Furthermore, encryption technology allows consumers to authenticate products and make sure that the items come from legal manufacturers and have passed all the required safety and certification standards. The authentication process usually occurs through the internet with the usage of a smartphone app or any other digitally encrypted code reader [22]. Ideally, counterfeit drugs would not have codes on packages at all, or the codes will not solicit consumers to the database, providing no information and making the authentication procedure impossible. Another advantage of the encrypted codes is that they make counterfeiters unable to enter the legal databases and make arbitrary codes. The main reason behind usage of individual codes is to provide unique ID for every package and prevent counterfeiters from either duplicating packages or repacking commodities with the purpose to deceive consumers. Counterfeiters exploit the internet as their selling vehicle, while legal parties can make use of advanced technologies [13] to secure legal merchandise and ensure customers' safety and secure IPRs. Implementation of advanced technologies for securing packages and preventing unauthorized access would increase the costs for counterfeiters and thus would reduce the amount produced and the share of fakes on the market [19].

\section{Conclusion}

Globalization calls for control. The security of pharmaceuticals nowadays is a paramount issue that has to be addressed by international bodies. Cooperation among state authorities, drug manufacturers, global and local retailers, and all relevant parties is required to prevent unauthorized trade of fake or spurious medications. Inaction in this regard leads to increased levels of corruption, supports other crimes, and endangers the lives of average people who are deceived. In order to strengthen the effort in fighting the global fake drug trade, a strong political will should exist, combined with efficient regulations and exact action plans that would involve the usage of the most updated technologies available. Enforcement of rules, penalties for violations, and international awareness also play an important role in preventing organized crime groups from selling fake drugs and being involved in other unethical practices. Technological advancements could be useful as a means to enhance traceability of products, verify their authenticity, and to ensure the accountably of producers, distributors and retailers. New 
solutions based on track and trace mechanisms actualized via encrypted codes and unified databases in combination with overt and covert means of security printing could create more obstacles for counterfeiters and increase costs they would need to incur to traffic and sell illegal merchandise on legal markets.

\section{References}

[1] Fenoff, R. and Wilson, J. (2009) Africa's Counterfeit Pharmaceutical Epidemic. Anti-Counterfeiting and Product Protection Program. A-CAPPP Paper Series.

[2] WHO (2016) Substandard, Spurious, Falsely Labelled, Falsified and Counterfeit (SSFFC) Medical Products. Fact Sheet.

[3] UNICRI (2014) Counterfeiting as an Activity Managed by Transnational Organized Crime and the Possible Re-Use of Seized Assets for the Promotion of Intellectual Property and Economic Growth. Ministry of Economic Development. Directorate-General for the Fight against Counterfeiting-Italian Patent and Trademark Office.

[4] European Commission (2014) Report on EU Customs Enforcement of Intellectual Property Rights, Results of EU Border 2013. Publications Office of the European Union, 2014.

[5] Interpol (2014) Against Oganized Crime. Interpol Trafficking and Counterfeiting Casebook 2014.

[6] OECD (2008) The Economic Impact of Counterfeiting and Piracy. Organisation for Economic Co-Operation and Development. 65-90, 152. https://www.oecd.org/sti/38707619.pdf

[7] Jackson, G., Patel, S. and Khan, S. (2011) Assessing the Problem of Counterfeit Medications in the United Kingdom. International Journal of Clinical Practice, 66, 241-250. http://dx.doi.org/10.1111/j.1742-1241.2011.02826.x

[8] AIFA (2016) L’Agenzia Italianadel Farmaco. http://www.agenziafarmaco.gov.it/

[9] Bronshtein, D. (2008) Counterfeit Pharmaceuticals in China: Could Changes Bring Stronger Protection for Intellectual Property Rights and Human Health? Pacific Rim Law \& Policy Journal Association.

[10] Bate, R. (2008) The Deadly World of Fake Drugs. Foreign Policy, No. 168 (Sep-Oct 2008), 56-62, 64-65. Washington Post. Newsweek Interactive, LLC.

[11] WHO (2011) One-Third of Antimalarial Medicines Tested in Six African Countries Fail to Meet International Quality Standards. Information Note: 25 February 2011.

[12] Alexandrova, L. (2014) Russia Needs Effective Remedy Against fake Drugs. Remedium.

[13] UNICRI (2012) Counterfeit Medicines and Organised Crime. United Nations Interregional Crime and Justice Research Institute.

[14] Interpol (2015) INTERPOL-Coordinated Operation Strikes at Organized Crime with Seizure of 20 million Illicit Medicines. Largest ever Operation Pangea VIII Targets Online Sales of Medicines and Medical Devices.

[15] Europol (2015) Situation Report on Counterfeiting in the European Union. A Joint Project between Europol and the Office for Harmonization in the Internal Market.

[16] OECD (2007) The Economic Impact of Counterfeiting and Piracy. Executive Summary.

[17] Probst, L., Frideres, L. and Pedersen, B. (2015) Traceability across the Value Chain New Anti-Counterfeiting Methods. European Union: Directorate-General for Internal Market, Industry, Entrepreneurship and SMEs. Directorate "Industrial Property, Innovation \& Standards”, Unit J.3 “Innovation Policy for Growth". Business Innovation Observatory 
Contract No 190/PP/ENT/CIP/12/C/N03C01.

[18] Fozley, M. (2005) Combating Counterfeit Drugs: A Concept Paper Effective International Collaboration. World Health Organisation. Health Technology and Pharmaceuticals.

[19] Lybecker, K.M. (2007) Combatting Counterfeit Pharmaceuticals in Developing Nations. Managerial and Decision Economics, 28, Economic and Policy Issues in the Pharmaceutical Industry (Jun-Aug 2007). http://dx.doi.org/10.1002/mde.1359

[20] Jenkins, J., Associates \& WP6 Partners (2007) Pharma Traceability Pilot Problem Analysis. BRIDGE-Building Radio Frequency IDentification Solutions for the Global Environment. Domino, GS1 UK, Melior Solutions Ltd, VeriSign Inc.

[21] Koh, R., Schuster, E., Chackrabarti I. and Bellman, A. (2003) Securing the Pharmaceutical Supply Chain White Paper. Auto-id Center. Massachusetts Institute of Technology.

[22] McCathie, L. (2004) The Advantages and Disadvantages of Barcodes and Radio Frequency Identification in Supply Chain Management. University of Wollongong Thesis Collections, University of Wollongong Research Online.

Submit or recommend next manuscript to SCIRP and we will provide best service for you:

Accepting pre-submission inquiries through Email, Facebook, LinkedIn, Twitter, etc.

A wide selection of journals (inclusive of 9 subjects, more than 200 journals)

Providing 24-hour high-quality service

User-friendly online submission system

Fair and swift peer-review system

Efficient typesetting and proofreading procedure

Display of the result of downloads and visits, as well as the number of cited articles

Maximum dissemination of your research work

Submit your manuscript at: http://papersubmission.scirp.org/

Or contact jss@scirp.org 